\title{
Antioxidant activity of the fruits of Pyracantha coccinea using ethanolic extract method
}

\author{
Alican Bahadır Semerci ${ }^{1}$ (D), Kenan Tunç ${ }^{1}$ (D) İbrahim Okur $^{2}$ (D)
}

Cite this article as:

Semerci, A.B., Tunç, K., Okur, İ. (2020). Antioxidant activity of the fruits of Pyracantha coccinea using ethanolic extract method. Food and Health, 6(1), 35-40. https://doi.org/10.3153/FH20005

\footnotetext{
Sakarya University, Department of Biology, Sakarya, Turkey

${ }^{2}$ Sakarya University, Department of Physics, Sakarya, Turkey
}

\section{ORCID IDs of the authors:}

A.B.S. 0000-0001-9502-9321

K.T. 0000-0002-9888-1453

İ.O. 0000-0003-2979-4310

Submitted: 05.09 .2019

Revision requested: 24.10 .2019

Last revision received: 04.11.2019

Accepted: 05.11.2019

Published online: 10.12.2019

\author{
Correspondence: \\ Kenan TUNÇ \\ E-mail: ktunc@sakarya.edu.tr
}

\begin{abstract}
Pyracantha coccinea Roem. (scarlet firethorn) is known as a medicinal plant that can be up to 3 $\mathrm{m}$ in height with lots of thorns, grown generally in South and Southeast Europe and Turkey. $P y$ racantha coccinea Roem is being used in folk medicine since its fruits have diuretic, cardiac and tonic properties. To determine the antioxidant level of the different parts of the plants takes interest in the current researches. In this study it has been aimed to evaluate the antioxidant and antimicrobial activity levels, $\mathrm{Fe}^{3+}$ reduction power and the total phenolic amount of the ethanolic extracts of the fruits of Pryacantha coccinea using DPPH scavenging, the disc diffusion, reduction power and Folin-Ciocalteu methods, respectively. $\mathrm{IC}_{50}$ value, which represents the $50 \%$ scavenging value of DPPH radical of prepared fruit extracts using the Maceration technique, is evaluated to be 36.53 $\mu \mathrm{g} / \mathrm{mL}$ The total phenolic content is determined to be $199.6 \mathrm{mgGA} / 100 \mathrm{~g}$ and $\mathrm{Fe}^{+3}$ ions are reduced to a certain amount for various concentration levels (from 20 to $100 \mu \mathrm{g} / \mathrm{mL}$ ). From the current research we have also found that the fruits of Pyracantha coccinea have no any antimicrobial activity. As a general result of the current study it has been concluded that the fruits of Pyracantha coccinea have extremely higher level of antioxidant activity depending upon the phenolic contents, showing that they can be used in various food and health applications.
\end{abstract}

Keywords: Antioxidant activity, Scavenging effect, Reducing power

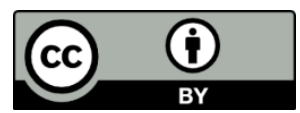

CCopyright 2020 by ScientificWebJournals Available online at

http://jfhs.scientificwebjournals.com 


\section{Introduction}

Pyracantha coccinea Roem. (scarlet firethorn) is a bush of up to $3 \mathrm{~m}$ in height with lots of thorns, grown generally in South and Southeast Europe, Italy, Balkans, Crimea, Caucaisans and Turkey at different altitudes. It is being used in folk medicine for its fruits' diuretic, cardiac and tonic properties (Fico et.al. 2000; Kambur and Tilki, 2010).

Lots of aromatic and curatic plants are known to have chemical complexes with antioxidant properties. Amongst these phenols and free-radical scavengers are the main source for the antioxidant materials.

Antioxidants are of importance especially in activating the scavenging reactive oxygen species, inhibiting their formation, binding transition metal ions and conserving the formation of $\mathrm{OH}$ and/or decomposition of lipid hydroperoxidase, so that repairing the damages in living organisms (Sadeghi et. al. 2015). They protect human against the infections and some degenerative ailments. The antioxidants are classified into two groups, namely natural and synthetic ones. The synthetic ones, e.g. butylated hydroxyl anisole and hydroxyl toluene, are commercial materials that can be purchased and can be used in 50-200 ppm level in nutrients and sometimes have side effects of being carcinogenic in living bodies (Ebrahimzadeh et. al. 2008).

They have also foundations of many other biological functions, such as anti-cancers, anti-inflammation and anti-aging (Zou et. al. 2016). The natural antioxidants are obtained from the allium sulphur compounds, the anthocyanins, beta carotene, the catechins, copper, the cryptoxanthins etc. The plants containing these natural antioxidant sources are being condensely studied by several researchers (Alshaal et. al. 2019; Parka et. al. 2019).

Free radical scavenging effect of antioxidants retards and/or inhibits the detriments in the living cells. This property of the antioxidants help anti-aging process in the living organisms and make them very alluring in scientific researches (Kumar et. al. 2017).

In this work it has been aimed to work out the antioxidant activity level, $\mathrm{Fe}^{+3}$ reduction power, total phenolic content and antimcrobial effect of Pyracantha coccinea fruits.

\section{Materials and Methods}

\section{Chemicals and Reagents}

All the chemicals and reagents (Folin-Ciocalteu, Gallic Acid, 2,2-diphenyl-1-picrylhydrazyl (DPPH), ethanol, Mueller Hinton Agar, Triptic Soy Broth, Saboraud Dextrose Agar, Sodium Carbonate, Ascorbic Acid) used in this study were of analytical grade and obtained from Merck Company, Germany.

\section{Plant of Ethanolic Extracts}

Fruits of Pyracantha coccinea were collected in Bahçelievler Neighborhood, Serdivan, Sakarya. 15 grams of fresh fruit was ground into a capped bottle and $150 \mathrm{~mL}$ of ethanol was added. The prepared mixture was stirred for 3 days at room temperature in the dark. The solvents in the extracts were evaporated by using rotary evaporator (Heidolph) under vacuum at $55^{\circ} \mathrm{C}$ for 15 minutes and the dried extracts were used for all investigations. The extract concentrations were adjusted by adding own solvent (ethanol) to each extract at the doses of $6400 \mu \mathrm{g} / \mathrm{mL}$ for the antimicrobial activity tests and $1000 \mu \mathrm{g} / \mathrm{mL}$ for the antioxidant activity and the total phenolics analyses, respectively.

\section{Antioxidant Activity (DPPH Assay)}

Antioxidant activity was determined by modified Blois method (Blois 1958). $1 \mathrm{~mL}$ of $0.004 \%$ solution of DPPH(2,2Diphenyl-1-picrylhydrazyl) radical in ethanol was mixed with $1 \mathrm{~mL}$ of extract solution (in ethanol). These solutions were kept in dark for 30 mins and the optical density was measured at $517 \mathrm{~nm}$ using a spectrophotometer. Throughout the process ethanol was used for the blank. The inhibiton percentage of the samples was calculated according to the following formula

$\%$ Inhibition $=\frac{A_{\text {control }}-A_{\text {sample }}}{A_{\text {control }}} \times 100$.

\section{Determination of Total Phenolic Content}

To determine the total phenolic content the Folin-Ciocalteu method was employed (Singleton and Rossi 1965). The 100 $\mu \mathrm{L}$ of ethanolic extract $(1000 \mu \mathrm{g} / \mathrm{mL})$ was mixed with $200 \mu \mathrm{L}$ of Folin-Ciocalteu (50\%) and was kept waiting for 2 minutes. Then, $1 \mathrm{~mL}$ of $2 \% \mathrm{Na}_{2} \mathrm{CO}_{3}$ solution was added and shaken well. The mixture was kept in a dark place for 1 hour. The absorbance of the mixture was measured at $760 \mathrm{~nm}$ by using a spectrophotometer (Shimadzu UV mini-1240). The total phenolic content values were determined from a calibration curve prepared with a series of gallic acid standards (50, 100, $200,300,400 \mathrm{mg} / \mathrm{L}$ ). The results were expressed as $\mathrm{mg}$ of $\mathrm{GAE} / 100 \mathrm{~g}$.

\section{Antimicrobial Activity}

For the determination of the antimicrobial activity, the disc diffusion method was used according to the National Committee for Clinical Laboratory Standards (NCCLS, 1997). The test microorganisms used in the present study were $\mathrm{Ba}$ cillus subtilis ATCC 6633, Salmonella typhimurium ATCC 14028, Escherichia coli ATCC 8739, Staphylococcus aureus 
ATCC 29213, Enterecoccus faecalis ATCC 29212, Staphylococcus epidermidis ATCC 12228, Pseudomonas aeruginosa ATCC 9027, Candida albicans ATCC 1029.

The suspensions with the density of 0.5 MacFarland density were prepared out of previously activated microorganism strains. The prepared suspensions have been inoculated into the Hinton agar by using swabs. Extracts obtained have been impregnated into the discs of $20 \mu \mathrm{L}$ and placed into MHA which were initially inoculated with microorganisms, followed by an incubation process at $37^{\circ} \mathrm{C}$ for $24 \mathrm{~h}$. Ethanolimpregnated discs were used as negative controls and the commercial antibiotic discs (Gentamicin and Amphotericin B) as positive ones. At the end of the incubation process, the diameters of the inhibition zone were measured by using electronic digital caliper.

\section{Reducing Power}

Reducing power of the ethanolic fruits extracts was quantified according to (Oyaizu 1985). Phosphate buffer of 1250 $\mu \mathrm{L}(0.2 \mathrm{M}, \mathrm{pH} 6.6)$ and potassium ferricyanide $\left[\mathrm{K}_{3} \mathrm{Fe}(\mathrm{CN})_{6}\right]$ of $1 \%$ were added onto the extracts of $500 \mu \mathrm{L}$ with the concentration of $20-100 \mu \mathrm{g} / \mathrm{mL}$ and this mixture has been incubated at $50{ }^{\circ} \mathrm{C}$ for 20 minutes. After this process, $1250 \mu \mathrm{L}$ of $10 \%$ trichloroacetic acid was added into the mixture and then centrifugated for 10 minutes at the speed of $2500 \mathrm{rpm}$. A supernatant part of $500 \mu \mathrm{L}$ has been taken from the mixture and distilled water of $1250 \mu \mathrm{L}$ and $\mathrm{FeCl}_{3} .6 \mathrm{H}_{2} \mathrm{O}$ of $250 \mu \mathrm{L} \%$ $1(\mathrm{w} / \mathrm{v})$ have been added on top of this. Absorbance was measured at $700 \mathrm{~nm}$ against a blank using a UV-Vis spectrophotometer.

\section{Statistical Analysis}

SPSS package program (version 20.0) has been used to analyse the data. The results have been given as mean values with standard deviations. During this evaluation process the $\mathrm{p}$ value of $<0.05$ has been accepted to be meaningful.

\section{Results and Discussion}

It is a fact that the number of antibiotics resisting to the microorganisms is getting less and less day by day. Therefore, lots of researchers are being employed in investigating the antimicrobial efficiencies of the plant extracts and they present their outcomes related to the antimicrobial properties of the plants in literature (Mouafo et al.2012; İnceçayır et. al. 2019). In the current work the effect of the fruit extracts of Pyracantha coccinea on the test microorganism has been investigated using the disc diffusion method. It has been observed that the obtained extract has no any atimicrobial activity on Bacillus subtilis, Salmonella typhimurium, Escherichia coli, Staphylococcus aureus Enterecoccus faecalis, Staphylococcus epidermidis, Pseudomonas aeruginosa, Candida albicans strains. In another work it has been reported that the fruit extract of Pyracantha coccinea has not shown any antimicrobial activity which is well correlated with our result (Uçar- Türker et. al. 2012). As a result, it has been concluded that the fruit extract of Pyracantha coccinea is not applicable as a natural antimicrobial agent.

Figure 1 shows the reducing power of Pyracantha coccinea ethanolic extracts as a function of their concentrations. Fe (III) reduction is often used as an indicator of electron-donating activity, which is an important mechanism of phenolic antioxidant reaction. The presence of reductants (antioxidants) in the herbal extracts causes the reduction of the $\mathrm{Fe}^{3+} /$ ferricyanide complex to the ferrous form (Niciforovic et. al. 2010). In this assay, depending on the reducing power of each compound the yellow colour of the test solution changes to various shades of green and blue. The existence of reducers in the test mixture results in a reduction of the $\mathrm{Fe}^{3+} /$ ferricyanide to the ferrous form. Reduction power of Pyracantha coccinea ethanolic extracts is found to be increased by raising the extract concentration level. The results obtained show that the reduction power of Pyracantha coccinea extracts supports the DPPH activity to a certain level.

Antioxidants are the enzymes and other oganic substances in foods that reduce the side effects of reactive oxygen and nitrogen on the normal physiological function in human body to a acceptaple level (Mustafa et. al. 2010). DPPH scavenging activity method to measure the antioxidant effect in plants is a method used frequently for this purpose. $\mathrm{IC}_{50}$ values and total phenolic content of Pyracantha coccinea fruits ethanolic extracts are illustrated in Table 1. Gallic acid equivalence in this study has been evaluated to be $199.6 \mathrm{mg} / 100 \mathrm{~g}$, whereas it has been determined to be 68.41 in a previous study (Keser 2014). Phenolics are the constituents of main antioxidants and their total contents are thougth to be directly related to their antioxidant efficiencies (Do et. al. 2014).

$\mathrm{IC}_{50}$ value representing the antioxidant amount to dicrease the DPPH concentration to $50 \%$ has been found to be 36.53 $\mu \mathrm{g} / \mathrm{mL}$ for Pyracantha coccinea extract and to be $3.2 \mu \mathrm{g} / \mathrm{mL}$ for ascorbic acid (as standard). When compared, the extract has been evaluated to be more effective in reducing the DPPH radicals.

In another work it has been found that the \%DPPH scavenging activity of different Pyracantha coccinea fruit extracts in the concentration level of $250 \mu \mathrm{g} / \mathrm{mL}$ is 78.73 (Keser 2014). DPPH levels of Pyracantha coccinea ethanolic and aqeuous fruit extracts collected in Konya city have been evaluated to be 6.12 and $2.05 \mathrm{mg} \mathrm{TEs} / \mathrm{g}$, respectively. In a study made by 

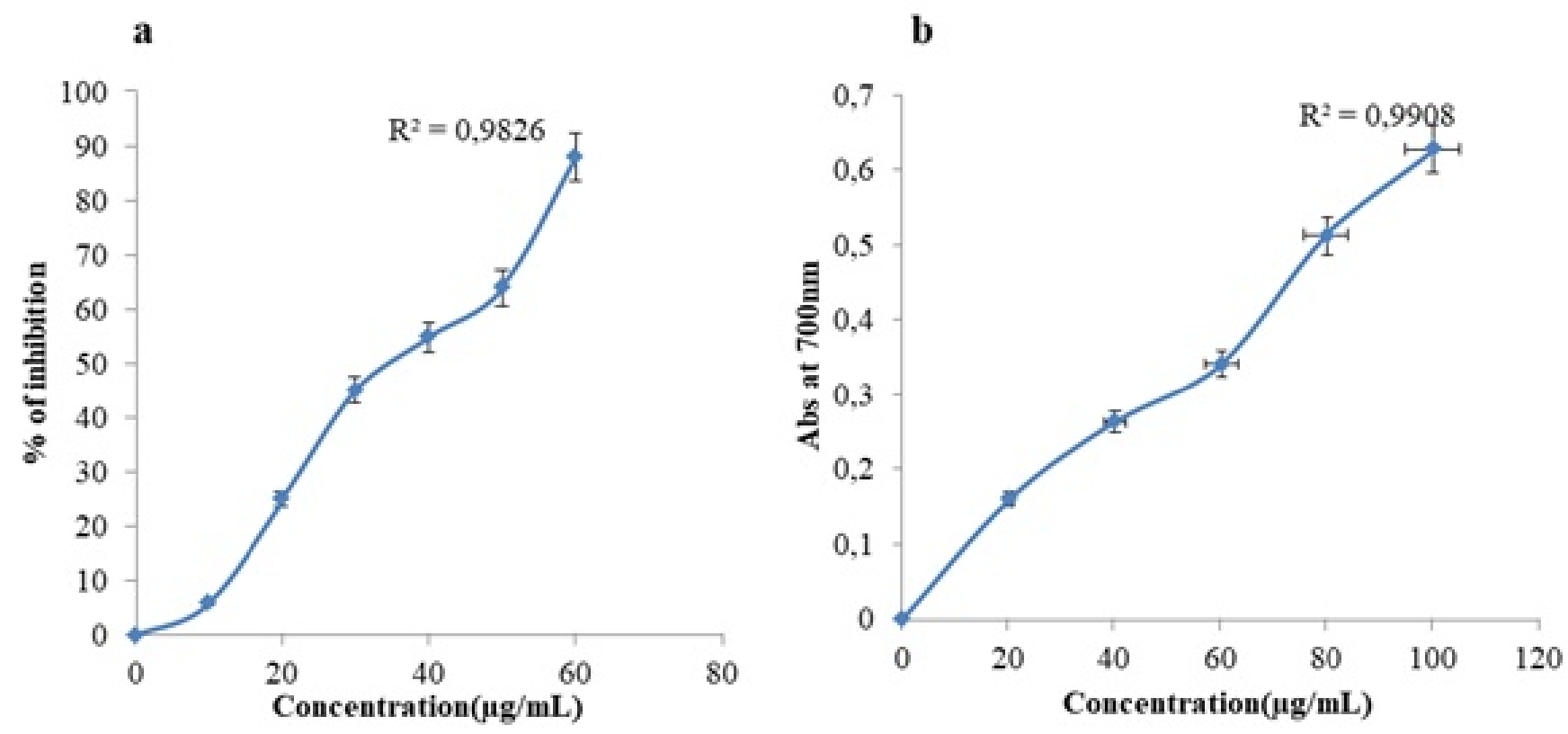

Figure 1. The results of (a) DPPH inhibition level (\%) and (b) reduction power of Pyracantha coccinea fruit extracts.

Tablo 1 IC50 values and TPC for the fruits of Pyracantha coccinea.

\begin{tabular}{lllll}
\hline \multirow{2}{*}{ Species } & \multicolumn{2}{l}{ Antioxidant Activity } & \multicolumn{2}{l}{ Total Phenolics } \\
& $\mathbf{I C}_{\mathbf{5 0}}(\boldsymbol{\mu g} / \mathbf{m L}) \pm \mathbf{S D}$ & $\mathbf{R}^{\mathbf{2}}$ & $\mathbf{m g G A} / \mathbf{1 0 0 g} \pm \mathbf{S D}$ & $\mathbf{R}^{\mathbf{2}}$ \\
\hline Pyracantha coccinea & $36.53^{\mathrm{b}} \pm 0.05$ & 0.98 & $199,6 \pm 4.5$ & 0.98 \\
Ascorbic acid & $3.2^{\mathrm{a}} \pm 0.01$ & 0.96 & - & -
\end{tabular}

Means \pm SD followed by the same letter, within the same form of antioxidant, are not significantly different $(p>0.05)$

Iranians the $\mathrm{IC}_{50}$ value of Pyracantha coccinea methanolic fruit extract has been determined as $4.61 \mathrm{mg} / \mathrm{mL}$ (Vahabi et. al. 2014; Sarıkürkçü et al. 2015). The discrepancies between these results are thought to be originated from the location and time of plant collection and the solvents used in preparation of the extracts. Furthermore the extraction method and conditions (temperature and time) may affect the antioxidant activity level.

\section{Conclusions}

We think that Pyracantha coccinea fruit extracts show strong antioxidant activity due to the presence of the total phenolic content and power reduction mechansims. From the current work together with the similar studies in the literature we conclude that the fruits of Pyracantha coccinea is a very good candidate to be used as a natural antioxidant source.

\section{Compliance with Ethical Standard}

Conflict of interests: The authors declare that for this article they have no actual, potential or perceived the conflict of interests.

Ethics committee approval: No ethics committee approval is needed.

\section{References}

Al Shaal, S., Karabet, F., Daghestani, M. (2019). Determination of the antioxidant properties of the Syrian olive leaves extracts and isolation oleuropein by HPLC techniques. Analytical and Bioanalytical Chemistry Research, 6(1), 97-110. https://doi.org/10.22036/ABCR.2018.137753.1220 
Blois, M.S. (1958). Antioxidant determinations by the use of a stable free radical. Nature, 181, 1199-1200.

https://doi.org/10.1038/1811199a0

Do, Q.D., Angkawijaya, A.E., Tran-Nguyen, P.L., Huynh, L.H., Soetaredjo, F.E., Ismadji S, Ju Y. (2014). Effect of extraction solvent on total phenol content, total flavonoid content, and antioxidant activity of Limnophila aromatic. Journal of Food and Drug Analysis, 22, 296-302.

https://doi.org/10.1016/j.jfda.2013.11.001

Ebrahimzadeh, M.A., Pourmorad, F., Hafezi, S. (2008). Antioxidant activities of Iranian corn silk. Turkish Journal of Biology, 32, 43-49.

Fico, G., Bilia, A.R., Morelli, I., Tome F. (2000). Flavonoid distribution in Pyracantha coccinea plants at diferent growth phases. Biochemical Systematics and Ecology, 28, 673-678. https://doi.org/10.1016/S0305-1978(99)00109-X

İnceçayir, D., Semerci, A.B., Mustafa, N., Tunç, K. (2019). Catalpa bignonioides metanolik çiçek ekstraktının biyolojik ve kimyasal aktivitesi. Türk Tarım ve Doğa Bilimleri Dergisi, 6(2), 230-234.

https://doi.org/10.30910/turkjans.557101

Kambur, S., Tilki, F. (2010). Pyracantha coccinea Roem. tohumunun çimlenme özelliklerinin belirlenmesi. III. Ulusal Karadeniz Ormanc1l1k Kongresi 20-22 Mayıs 2010 Cilt: II Sayfa: 785-791.

Keser, S. (2014). Antiradical activities and phytochemical compounds of firethorn (Pyracanthacoccinea) fruit extracts. Natural Product Research, 28(20), 1789-1794.

https://doi.org/10.1080/14786419.2014.942304

Kumar, S., Yadav, A., Yadav, M., Yadav, J.P. (2017). Effect of climate changeon phytochemical diversity, total phenoliccontent and in vitro antioxidant activity of Aloevera (L.) BMC Research Notes, 10, 60.

https://doi.org/10.1186/s13104-017-2385-3

Mouafo Tekwu, E., Costant Pieme, A., Penlap Beng, V. (2012). Investigations of antimicrobial activity of some Cameroonian medicinal plantextracts against bacteria and yeast with gastrointestinal relevance. Journal of Ethnopharmacology, 142, 265-273.

https://doi.org/10.1016/j.jep.2012.05.005

Mustafa, R.A., Abdul Hamid, A., Mohamed, S., Abu Bakar, F. (2010). Total phenolic compounds, flavonoids, and radical scavenging activity of 21 selected tropical plants. Journal of Food Science, 75, 28-35.

https://doi.org/10.1111/j.1750-3841.2009.01401.x

National Committee for Clinical Laboratory Standards (1997). Performance standards for antimicrobial disk susceptibility tests. Approved standard M2-A6. Wayne, Pa: National Committee for Clinical Laboratory Standards; 1997.

Niciforovic, N., Mihailovic, V., Maškovic, P., Solujic, S., Stojkovic, A., Pavlovic, DM. (2010). Antioxidant activity of selected plant species; potential new sources of natural antioxidants. Food and Chemical Toxicology, 48, 3125-3130. https://doi.org/10.1016/j.fct.2010.08.007

Oyaizu, M. (1986). Studies on product of browning reaction prepared from glucose amine. Japanese Journal of Nutrition, 44, 307-315.

https://doi.org/10.5264/eiyogakuzashi.44.307

Parka, J., Rhob, S.-J., Kima, Y.-R. (2019). Enhancing antioxidant and antimicrobial activity of carnosic acid in rosemary (Rosmarinus officinalis L.) extract by complexation with cyclic glucans. Food Chemistry, 299, 125119. https://doi.org/10.1016/j.foodchem.2019.125119

Sadeghi, Z., Valizadeh, J., Azizian Shermeh, O., Akaberi, M. (2015). Antioxidant activity and total phenolic content of Boerhavia elegans (choisy) grown in Baluchistan, Iran. Avicenna Journal of Phytomedicine, 5(1), 1-9.

Sarıkürkçü, C., Tepe, B. (2015). Biological activity and phytochemistry of firethorn (Pyracantha coccinea M.J. Roemer). Journal of Functional Foods, 19, 669-675.

https://doi.org/10.1016/j.jff.2015.10.004

Singleton, V.L., Rossi, J.A. (1965). Colorimetry of total phenolics with phosphomolybdic-phosphotungstic acid reagents. American Journal of Enology and Viticulture, 16, 144-158. 
Ucar-Türker, A., Birinci-Yildirim, A., Pehlivan-Karakas, F. (2012). Antibacterial and antitumor activities of some wild fruits grown in Turkey. Biotechnology \& Biotechnological Equipment, 26(1), 2765-2772.

https://doi.org/10.5504/BBEQ.2011.0156

Vahabi, L., Monajemi, R., Shahanipou, K., Moridnia, A., Mortazavifar, F. (2014). Studying the cytotoxic effect of methanolic extract of Pyracantha coccinea M. Roemer fruit on HeLa cell line and antioxidant capacities and total phenol contents of methanolic and aquatic extract of this fruit. Bulletin of Environment, Pharmacology and Life Sciences, 8, SEMAR.

https://doi.org/10.13005/bpj/564

Zou, Z., Xi, W., Hu, Y., Nie, C. Zhou, Z. (2016). Antioxidant activity of citrus fruits. Food Chemistry, 196, 885-896. https://doi.org/10.1016/j.foodchem.2015.09.072 